\title{
UNA VISIÓ EPICÚRIA DE LA VELLESA A «EL CONTE EXPLICAT PEL MERCADER» DE GEOFFREY CHAUCER
}

\author{
MONTSERRAT JUFRESA \\ Universitat de Barcelona \\ mjufresa@ub.edu
}

RESUM

«El conte explicat pel Mercader», inclòs a Els contes de Canterbury de Geoffrey Chaucer, relata el casament entre un vell cavaller, Gener, i una núvia jove, Maig. La història acaba feliçment, amb un adulteri de l'esposa acceptat pel marit. El caràcter del vell Gener està descrit amb els atributs d'un practicant de la doctrina epicúria, tal com aquesta era entesa a l'Edat Mitja.

PARAULES CLAU: Chaucer, epicureisme, vellesa, matrimoni, Ciceró.

\section{AN EPICUREAN INSIGHT ON OLD AGE: “THE MERCHANT'S TALE” BY GEOFFREY CHAUCER}

\section{ABSTRACT}

"The Merchant's Tale" one of the stories in The Canterbury Tales by Geoffrey Chaucer, relates the marriage between the old gentleman January and the young bride May. The story ends with the adultery of the wife, happily assumed by her husband. The character of old January shows strong features that comply with the attributes of an epicurean adept, in the way the epicurean doctrine was understood in Middle Ages.

KEYWORDS: Chaucer, epicurianism, old age, pleasure, marriage, Cicero.

El llibre Els contes de Canterbury, escrit entre 1380 i 1387 per Geoffey Chaucer, ${ }^{1}$ és un enfilall d'històries en vers relatades per un grup de pelegrins durant les jornades del viatge que els conduirà al santuari de Canterbury per venerar la tomba de Sant Tomàs Beckett. ${ }^{2}$

${ }^{1}$ The Canterbury Tales són una obra inacabada, de la que no existeix un manuscrit definitiu. Aquesta obra va gaudir de gran popularitat i se n'han conservat uns noranta manuscrits més o menys parcials.

Els reconeguts com a més valuosos són el manuscrit Ellesmere, que conté nombroses miniatures, i es conserva a la Huntington Library de San Marino (California) i el manuscrit Hengwrt, guardat a la Biblioteca Nacional de Gal-les. L'edició de Fisher (1977) està basada en el manuscrit Ellesmere.

2 Tomàs Beckett, arquebisbe de Canterbury, va morir l'any 1170 assassinat a la catedral per ordre del rei Enric II, a qui havia servit com a canceller i amb qui havia mantingut una relació d'amistat. Aquesta mort, que comportava a més la profanació d'un lloc sagrat, va commoure tot el món cristià i Tomàs Beckett fou proclamat sant al cap de poc temps, el 1173. Durant els segles XIII, XIV i XV la seva tomba esdevingué un lloc de peregrinació freqüentat per persones de totes les classes socials. Vegi's Guardia (2016: 23-31). 
A la secció quarta del llibre hi trobem el conte explicat pel Mercader. ${ }^{3}$ L'amic Josep Maria Jaumà em va fer arribar recentment una seva traducció catalana i en vers d'aquest conte, ${ }^{4} \mathrm{i}$ en llegir-lo vaig pensar que oferia una visió força suggestiva, no exempta d'ironia i de crítica, de com podia entendre la vellesa un epicuri. Això és el que miraré d'explicar.

Primer de tot cal que recordem la història. El protagonista és un home de seixanta anys - per a l'època, molt vell-, ric i amb possessions, de nom Gener, que s'ha mantingut solter tota la vida, encara que no apartat de les dones. El narrador el descriu així:

Hi havia una vegada a Llombardia,

Un digne cavaller, nat a Pavia,

On residia amb gran prosperitat;

Amb seixanta anys, no s'havia casat:

Seguia sempre el seu propi desig

Amb les dones, que era el seu apetit. ${ }^{5}$

Un bon dia, però, sigui per devoció o per repapieig - apunta l'autor - , li agafà delit per casar-se, convençut que el matrimoni li aportaria felicitat infinita, que seria el seu Paradís a la terra, i a més el lliuraria de pecar, perquè «aquell que fa vida de casat, viu en un món beneït i ordenat». ${ }^{6}$ Això sí, el casament havia de ser amb una noia ben jove, res de dones de més de trenta anys, que la saben massa llarga. Menystenint les advertències de Teofrast, ${ }^{7}$ que:

\footnotetext{
No et casis", escrigué, "per estalviar

Creient que gastaràs menys capital.

Un criat guardarà amb més diligència

Els teus diners, que no la teva esposa,

Que et reclamarà sempre la meitat.

I, Déu no ho vulgui, si et poses malalt,

Els bons amics o algun criat fidel

$\mathrm{T}^{\prime}$ atendran millor que ella, certament,

Protegint els teus béns com ho han fet sempre.

I si admets una esposa a casa teva
}

\footnotetext{
${ }^{3} \mathrm{El}$ conte potser va ser escrit per a un narrador diferent. En el pròleg actual, el Mercader evoca la seva experiència personal que l'ha omplert de prevencions contra el matrimoni, aspecte que el connecta amb el contingut de la historia que explicarà, Cooper (1989).

4 «El conte explicat pel Mercader», traducció catalana inèdita de Jaumà (2018). La traducció segueix el text anglès de Chaucer inclòs a Abrams (1973).

5 «El conte explicat pel Mercader», vv. 1-6.

${ }^{6}$ id., vv. 39-40.

7 Teofrast (370-288 a. C.) fou deixeble i successor d'Aristòtil al capdavant del Liceu. Durant l'edat mitjana li fou atribuïda l'obra Liber aureolus de nuptiis, de marcat caràcter misogin, i que només coneixem per un resum de Sant Jeroni, Epistola I, 41. No hi ha cap evidència que Teofrast fos l'autor del Liber, però entre els títols de la seva extensíssima obra, perduda en la seva major part, hi figuren dos escrits Sobre l'amor i un Sobre la felicitat (D.L. V. 42-50), també perduts.
} 
Pots fàcilment acabar sent cornut. ${ }^{8}$

Malgrat tot, i recolzant-se en testimonis de la Bíblia, ${ }^{9}$ de Sèneca ${ }^{10}$ i de Cató ${ }^{11}$, Gener persistí en la seva idea, i convocà els amics per explicar-los les seves intencions.

Amics meus, ja m'he fet vell i gris,

I Déu sap que sóc vora de la tomba;

He de posar-me a pensar en la meva ànima.

He malgastat la carn ben follament

$[\ldots]$

I ara ho corregiré, gràcies a Déu,

Car em proposo ser un home casat,

Tan de pressa com pugui, molt aviat,

Amb una noieta tendra i bella. ${ }^{12}$

$[\ldots]$

No vull cap dona que tingui trenta anys,

Són només palla i pinso mustiat;

Ni vull tampoc cap vídua; Déu ho sap:

Són tan hàbils en l'art de fer equilibris

Que et poden injuriar tant com els plagui;

Amb elles no viuria mai en pau. ${ }^{13}$

Gener gaudia d'una bona salut, i així ho explicà als amics, buscant la seva aprovació:

Perquè gràcies a Déu puc ufanar-me

D'uns membres forts i que encara són aptes

Per fer tot el que a un home correspon. ${ }^{14}$

$[\ldots]$

No em sento vell, sinó ben dret i fort,

El meu cor i els meus membres són tan verds

Com podem veure tot l'any el llorer. ${ }^{15}$

Aquesta constatació, tanmateix, no evità que la decisió generés controvèrsia, concretada en els arguments contraposats dels seus germans,

8 «El conte explicat pel Mercader», vv. 52-62.

${ }^{9}$ La Biblia és un referent constant i obligat en tota la literatura medieval.

${ }^{10}$ Sèneca (4 a. C.-65 p. C.), fou un filòsof, polític, i escriptor romà. L'afirmació que aquí li atribueix Chaucer, «res no supera una esposa complaent», prové en realitat de Fulgenci, Myth. I, 22. Més endavant, als vv. 313-315, Justí apel-la a l'autoritat del filòsof romà per reforçar els seus arguments misògins.

${ }^{11}$ Dionisi Cató (s. III-IV p. C) és l'autor a qui s'atribueix l'obra Distycha de Moribus, que a l'Edat Mitja es creia que havia estat escrita per Cató el Vell o Cató el Jove. El Cató va ser un llibre de text en llatí molt popular, perquè a més de servir per aprendre la llengua tenia un contingut moral. Chaucer el cita 12 vegades com una autoritat als Contes de Canterbury.

12 «El conte explicat pel Mercader», vv. 188-195.

13 id., vv. 210-215.

14 id., vv. 247-249.

15 id., vv. 254-256. 
Placebo i Justí. ${ }^{16}$ Placebo l'adulà i li donà la raó. Justí, en canvi, li parlà amb franquesa i després de citar Sèneca i explicar les llàgrimes que a ell mateix li havia costat el matrimoni, li recomanà que s'ho pensés bé abans de casar-se, dient-li que tenia massa edat per fer-ho amb una noia ben plantada. Però Gener no feu cas del seu germà, i dia a dia, la imaginació i una alerta agusada li ompliren el cap d'imatges del casament, perquè - diu Chaucer - l'amor és cec i res no veu. ${ }^{17}$ De manera que el vell cavaller acabà per triar una noia jove i bonica, la Maig:

I un pic hagué posat en ella el cor, cregué que no n'hi havia cap millor. ${ }^{18}$

Aleshores tornà a reunir els amics, i els demanà ajuda per a l'organització del casori, però així mateix els exposà l'únic dubte que li burxava la consciència. Estava segur que duria una vida tan feliç en el seu matrimoni, que seria com estar-se al cel, però, es preguntava:
Si pujar al cel demana esforç, Passar tribulacions i grans penúries ¿com podré jo, vivint entre delícies, (com viuen els casats amb les esposes)
Arribar on Crist té la seva glòria?19
En aquest punt,
Justí, que abominava tal follia,
Respongué ràpid amb plasenteria:
[...]
Si aquest és, senyor, l'obstacle
I no n'hi ha d'altre, Déu farà un miracle
i amb misericòrdia farà que
Quan moris se t'enterri santament
Penedint-te d'haver viscut casat.
[...]
Per tant, senyor, el meu millor consell
És no desesperar, i recordar
Que la muller pot ser també un dolor

\footnotetext{
${ }^{16}$ El noms dels germans són parlants: Placebo, «El que vol agradar» i Justí, «El que parla amb encert».

${ }_{17}$ Plató considerà l'amor del bell i just com un camí que conduïa a la contemplació del Bé, i digué que calia guardar-se de l'amor d'un mateix perquè no ens permetia jutjar amb claredat

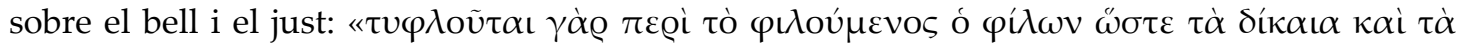
$\kappa \alpha \lambda \grave{\alpha} \kappa \alpha \kappa \tilde{\omega} \varsigma \kappa \varrho i ́ v \varepsilon l »($ Leg. 731e). Els poetes llatins referiren la imatge de l'amor cec a la passió amorosa, entre altres, Ov., Fasti II, 762; Va. Max., Argonautica VI, 454. L'Edat Mitja elaborà la tradició platònica en la teoria de l'amor cortès i també en l'amor de la Verge Maria, però en representà la vessant carnal amb la imatge de l'amor cec associada a la pèrdua de valors morals i al mal. Vegi's Panofsky (1939).

18 «El conte explicat pel Mercader», vv. 395-396.

$19 \mathrm{id.,}$ vv. 438-442.
} 
Un fat diví i mortificador! ${ }^{20}$

No cal dir que Gener seguí el seu propi criteri, es casà amb la jove Maig, ${ }^{21}$ a qui omplí de presents, i durant un temps va ser immensament feliç. No obstant, un jove anomenat Damià, ${ }^{22}$ que servia el cavaller feia ja uns anys, estava tan encisat de la Maig que el casori l'omplí de dolor, gairebé embogí, i acabà que no podia moure's del llit. Preocupat pel seu servent, Gener envià la muller a interessar-se pel malalt, i Damià aprofità per declarar-li el seu amor. La noia, commoguda per la intensa passió del minyó, malgrat que el marit no li permetia allunyar-se, maquinà una estratagema per poder complaure el desig de l'enamorat.

Tornem ara a fixar-nos en Gener, que és qui ara més ens interessa. Segons remarca el narrador, el noble Gener, tenint en compte el criteri d'alguns autors - que aquesta vegada no identifica pel nom $-{ }^{23}$ i que afirmen que la felicitat consisteix en el plaer:

Diu un savi que la felicitat

es basa en el plaer, i per tant ell,

el distingit Gener, amb el seu poder,

honestament, com li corresponia,

somniava de viure entre delícies ${ }^{24}$

ho disposà tot per viure d'una manera absolutament plaent, però això sí, de manera honesta com era d'esperar d'un cavaller. Els seus vestits i mobles eren com els d'un rei, i entre aquestes coses honestes es feu construir un jardí cercat $\mathrm{d}^{\prime}$ un mur de pedra, ${ }^{25}$ un jardí preciós com mai no s'havia vist i que no hauria ni pogut concebre l'autor del Roman de la Rose. ${ }^{26}$ I com que era tan bonic, en aquest

\footnotetext{
20 id., vv. 445-446; vv. 449-453; vv. 458-461.

${ }^{21}$ Els noms dels protagonistes també són parlants: l'hivern i la primavera, i ens ofereixen una línia d'interpretació que no condemna la conducta de Maig, perquè és evident la incompatibilitat amorosa entre la vellesa i la joventut.

${ }^{22}$ Damià és el nom d'un dels sants protectors dels metges. En el conte, Damià, amb la seva acció dalt de la perera serà, segons explica la Maig, l'instrument de la curació de la ceguera de Gener. Vegi's Caie (1982).

${ }^{23}$ Es refereix sens dubte a Epicur, però Chaucer aquí no ha volgut explicitar-ne el nom, el text anglès atribueix a «somme clerkes» l'afirmació «that felicitee stant in delyt». Tanmateix trobem aquest filòsof citat pel seu nom en el «Pròleg General» dels Contes de Canterbury, vv. 331-338, quan ens és presentat el Terratinent, un dels pelegrins que relataran les històries.

24 «El conte explicat pel Mercader», vv. 809-813.

${ }^{25}$ La imatge del jardí o el prat amb arbres i flors va lligada a la de l'amor ja des d'Homer i Safo. En el context d'aquesta historia també fa referència al Jardí de l'Eden on Eva es deixà temptar per la serp i arrossegà Adam a cometre el pecat original. D'altra banda, l'epicureisme era anomenat «la filosofía del Jardí», perquè Epicur (342-270 a. C.) preconitzava una vida senzilla i austera en què els adeptes conreaven verdures a l'hort $-\kappa \tilde{\eta} \pi \mathrm{r} \varsigma-$ de la casa del barri d'Atenes on vivien de manera comunitària.

${ }^{26}$ El Roman de la Rose és un poema al-legòric de 22.000 versos, escrit en francès al s. XIII, iniciat per Guillaume de Lorris i continuat per Jean de Meun. L'acció es desenvolupa en el marc d'un
} 
extraordinari jardí solien passejar-hi, sense ser vistos, Plutó i Prosèrpina. ${ }^{27} \mathrm{Al}$ vell Gener el jardí també li agradava molt, no volia que hi entrés ningú i en duia sempre la clau a sobre, per poder-hi anar quan li plagués:

Al temps d'estiu cap allà se n'anaven

Ell i la Maig; i ningú més no hi entrava;

I algunes coses que no feia al llit

Les acomplia ràpid al jardí. ${ }^{28}$

Però com que el plaer d'aquest món mai no dura, comenta l'autor, el noble i generós Gener en mig de tant de benestar i tant de deler es quedà de cop i volta cec. El cavaller plorava i gemegava endut de gelosia, pensant que la Maig no cometés algun disbarat. Al cap d'un temps, tanmateix, la seva tristor amainà, per més que no la gelosia, que el duia a mantenir l'esposa sempre al seu costat i no deixar-la anar sola ni un moment. Això feia plorar la tendra Maig, i desesperava en Damià, que no podien parlar perquè en Gener ho escoltava tot. Per sort s'escrivien missives i es feien signes, de manera que la Maig s'enginyà per donar una còpia de la clau del jardí al seu enamorat. I succeí, tal com ja deia Ovidi, que l'amor sempre sap trobar un viarany, per perillós que sigui, i aquell mes de juny a Gener li vingué un gran delit d'anar a passar-ho bé al seu jardí. Així que digué a la seva esposa:

\footnotetext{
Desperta, esposa meva,

Amor del cos, caritativa dama

$[\ldots]$

Vine i fruïm plegats dels nostres goigs..$^{29}$
}

La Maig, amb signes, va tenir temps d'avisar en Damià, que corregué a amagar-se al jardí darrera d'un arbust. Quan en Gener i la Maig arribaren al jardí, el vell tornà a declarar el seu amor a la noia, i li prometé deixar-li totes les seves possessions si no l'enganyava mai. Però mentre pronunciava promeses de fidelitat, la Maig feia signes a en Damià que s'enfilés a una perera plena de fruits. Entre tant, en aquell brillant dia de juny Plutó i Prosèrpina també havien triat el

somni, i té lloc en un jardí, on el protagonista s'enamora de la Rosa i ha de vèncer múltiples obstacles fins assolir conquerir la torre en la que està empresonada. El jardí és equiparat al Paradís i a la felicitat. Aquesta obra va ser una de les més llegides del seu temps, i se n'han conservat nombrosos manuscrits de l'època. La influencia clàssica impregna tot el poema. Va ser traduït a l'anglès, parcialment, per Geoffrey Chaucer.

${ }^{27}$ El matrimoni format per Plutó i Prosèrpina també és entre un vell i una joveneta, que ha estat raptada mentre collia flors en un prat. Per això Plutó es mostra solidari amb Gener, mentre Prosèrpina ajuda Maig i totes les dones en general. Els déus tenen una funció de mitjancers i faciliten un acabament «feliç», o millor dit, no violent, de manera similar al «deus ex machina» $\mathrm{d}$ 'algunes tragèdies gregues.

28 «El conte explicat pel Mercader», vv. 837-840.

29 id., vv. 926-927; v. 936. 
jardí per passar-hi l'estona, i saberuts com són els déus, preveieren el que estava a punt de passar. ${ }^{30}$ Aleshores Plutó és compadí de Gener i digué:

No veieu l'honorable cavaller?

$\mathrm{Ai}$, las, per mor de ser cec i xaruc

El propi patge el farà avui cornut.

$[\ldots]$

Amb el poder que tinc, ara faré

Que aquest ancià cavaller, cec i digne,

Pugui recuperar la seva vista

Quan la dona li faci la malifeta. ${ }^{31}$

Però això no acabà de semblar prou bé a Prosèrpina que li replicà:
Això faràs?
Doncs juro pel meu avi,
Que faré que ella sàpiga respondre
- no sols ella, també les altres dones-
Quan les enxampin en alguna culpa.
Amb cares sèries trobaran l'excusa,
Avergonyint aquell que les acusa. ${ }^{32}$

I així varen quedar. Mentre tant, la jove Maig, arribats a sota la perera, començà a sospirar, dient que li havia agafat un gran apetit per menjar-se una pera. ${ }^{33}$ Gener l'ajudà a enfilar-se a l'arbre, on Damià l'esperava ben a punt. Quan Plutó s'adonà del què succeïa, retornà tot seguit la vista a Gener, que molt feliç, per dir-li-ho a l'esposa girà els ulls cap amunt, a la perera, i els veié a ella i a Damià «col-locats com no es pot pas explicar». Però la Maig, davant dels retrets del marit, de seguida respongué:
Senyor, què us passa?
Considereu i adoneu-vos amb calma
Que us ajudo a curar els vostres ulls cecs.
$[\ldots]$
Em van dir que, per curar-vos la vista,
Perquè poguéssiu veure-hi bé, havia
De lluitar contra un home en un perer.
Déu sap que ho feia amb la més bona fe. ${ }^{34}$

De cop Gener es resistí a creure les explicacions de Maig, però a la fi quedà convençut que no havia vist el què havia vist i acceptà els arguments de la muller,

\footnotetext{
30 Per a aquest episodi Chaucer fa servir materials extrets de l'obra de Claudià (370-405 p. C.) De raptu Proserpinae. Vegi's Gray (2003).

31 «El conte explicat pel Mercader», vv. 1131-1133; vv. 1135-1138.

32 id., vv. 1141-1147.

${ }^{33}$ El delit per menjar una pera suggereix que la muller està embarassada, cosa que el marit continua creient al final del conte.

34 «El conte explicat pel Mercader», vv. 1245-1247; vv. 1249-1252.
} 
que afirmava que un home que acaba de recuperar la vista, igualment com aquell que es desperta d'un son, no hi veu prou clar i pot errar en el seu judici dels fets. I al final el narrador es pregunta: «Qui és, com Gener, tan feliç ara?»,35 i ens explica com el vell cavaller abraça i petoneja la muller, li acaricia suaument el ventre i se l'enduu al palau amb ell.

Així s'acaba la història contada pel Mercader. Els crítics literaris hi distingeixen tres parts, una primera que és un encomi del matrimoni en boca de Gener, una segona en forma de debat medieval amb els arguments a favor i en contra del matrimoni i de les dones a càrrec de Placebo i Justí, i una tercera part que és com un fabliau, amb els ingredients habituals d'adulteri i engany. La presència de les dues parts primeres indicarien que la història de la tercera pot ser llegida com un exemplum, que al seu torn conté també un aition, l'episodi de Plutó i Prosèrpina, una explicació de la capacitat de les dones per enganyar i per enraonar massa. Tot plegat té un aire molt semblant a les novelle de Boccaccio $^{36} \mathrm{i}$ a d'altres contes populars on hi és present l'episodi de la perera. ${ }^{37}$

«El conte explicat pel Mercader» ens parla sens dubte del matrimoni i de l'amor, però ho fa presentant un cas especial i sovint problemàtic: el d'un vell que es casa amb una joveneta, ${ }^{38}$ un fet que no per ser socialment acceptat deixa de tenir un vessant poc natural, tal com indiquen els noms dels protagonistes. Davant de la manera com es desenvolupa i acaba la història, els lectors podem pensar diverses coses: en primer lloc, que l'autor, Chaucer, tal com mescla elements literaris de la tradició clàssica i de la tradició cristiana, amb humor, ironia $\mathrm{i}$ un pèl d'heterodòxia, també fa una amalgama entre moral cristiana $\mathrm{i}$ filosofia pagana. És així que el vell cavaller - que no vol renunciar al plaer, o a la il·lusió, que li causa la seva dona - al final accepta el fet de ser cornut, qui sap si com la via de patiment dins del matrimoni que li permetrà l'accés al Paradís quan es mori, tal com li ha vaticinat el seu germà Justí.

Segonament, el vell Gener sembla ben bé un exemple d'adepte de l'epicureisme, entès com es feia a l'Edat Mitja, limitant-lo a l'aspecte de gaudi dels sentits, ${ }^{39}$ com indiquen els versos 809-813 que ja hem comentat. Però Chaucer

\footnotetext{
35 id., v. 1289.

${ }^{36}$ La historia de Decameró VII, 9 tracta un tema similar: un triangle entre un marit vell, Nicòstrat, una esposa jove, Lídia, i un parent minyó, Pirrus. També s'hi desenvolupa l'engany emparat per la perera, però el to és molt més descarnat i cruel, i no hi és present el motiu de la ceguera del marit com una al·lusió a la ceguera de l'amor.

37 Podem trobar variants d'aquesta història per tot Europa, en algunes el paper de Plutó i Prosèrpina és representat per Sant Pere i Jesús. Vegi's Cooper (1989).

${ }^{38}$ Es converteix en un tema literari, profusament tractat. Com a exemple recordem les obres de teatre L'école des femmes, de Molière, al s. XVII, i El sí de las niñas, de Leandro Fernández de Moratín, a l'inici del s. XIX. En ambdues obres el conflicte es resol de manera que el pretendent vell es retira i els joves poden viure obertament el seu amor.

39 Jones (1989: 135-141) explica que els lectors medievals van poder tenir coneixement d'Epicur a través de Diògenes Laerci, Lucreci i Ciceró, De finibus. Però sembla que la major part del que se sabia sobre Epicur deriva de Boeci, de les Etimologies d'Isidor, o de les obres de Beda i Raban
} 
hi afegeix uns trets de bonhomia, presents també en la descripció del personatge del Terratinent que ha fet al Pròleg General, de qui diu explícitament que és un seguidor d'Epicur: ${ }^{40}$
A Frankelyn was in his company;
Whyt was his berd, as is the dayesye.
Of his complexioun he was sangwyn.
Wel loved he by the morwe a sop in wyn
To liven in delyt was ever his wone
For he was Epicurus owne sone.
That held opinioun, that pleyn delyt
Was verraily felicitee parfyt. $^{41}$

De Gener se'ns ha mostrat que procura gaudir sense fer mal a ningú - recordem que el narrador el qualifica d'honest més d'una vegada. Encara que és ric no és avar, ni és desagradós, es preocupa pel seu criat, és generós amb els amics i regala bona part dels seus béns a la seva dona. L'únic que desitja és fruir de la taula, del llit i del seu jardí, ${ }^{42}$ aplicant aquella màxima d'Epicur:

Em diuen que els impulsos de la carn t'inclinen excessivament als plaers de l'amor. Però tu, mentre no violis les lleis, no ofenguis els bons costums, no afligeixis qui t'està a la vora, no perjudiquis el teu cos, $\mathrm{i}$ de la teva fortuna no en malgastis fins $\mathrm{i}$ tot allò que és necessari, satisfés de la manera que més t’agradi els teus impulsos. No obstant, és difícil no caure almenys en un d'aquests casos: perquè els plaers de l'amor no són mai beneficiosos, podem estar contents si no ens perjudiquen. ${ }^{43}$

En el cas de Gener, els seus plaers han tingut evidentment un cost per a tots els participants - ell mateix és enganyat, la Maig està afligida i Damià s'ha posat malalt - però gràcies a la intervenció dels déus, les conseqüències no seran tràgiques, sinó que tindrem un «ménage à trois» ben avingut, no segons els principis de la moral cristiana, sinó més aviat dels de l'ètica epicúria o estoica que aconsellen viure d'acord amb la naturalesa. Perquè d'alguna manera el poeta és conscient que el natural és l'amor entre gent de la mateixa edat, però en el cànons

\footnotetext{
Maur que reprodueixen extractes de Lucreci. Això creà una imatge d'Epicur com a científic amb un cert grau de legitimitat. Al mateix temps s'obrí pas una altra imatge, la d'Epicur com a màxim representant de la sensualitat, d'amo de cuines, tavernes i bordells.Vegi's Highet (1986).

40 The Canterbury Tales, «Prologue», vv. 331-38, Benson (1989).

${ }^{41}$ «Al grup hi havia un terratinent, de barba blanca com pètals de margarida. Era de complexió sanguínia, al matí li abellia pa remullat amb vi. Viure en el plaer era el seu desig, com un vertader fill d'Epicur, que opinava que la felicitat perfecta és la plenitud del plaer».

${ }^{42}$ Joan de Salisbury (1120-1180), bisbe i escriptor, secretari de Tomas Beckett, a la seva obra Policraticus VIII, 16, dóna una descripció del jardí dels epicuris com un Paradís regat pels rius de la luxúria, de l'amor a la riquesa, del desig de tranquil-litat i de confort, i finalment de tirania i desig de celebritat. Vegi's Highet (1986). Potser hi ha algun element d'aquesta imatge en el jardí de Gener i en el mateix personatge, de qui s'ha dit que té uns mobles i un palau que són com els d'un rei.

${ }^{43}$ Epicur., Sent. Vat., 51. Trad. de Jufresa (2008).
} 
de l'Edat Mitja no hi entra la idea de l'amor en la parella matrimonial. És per això que la jove Maig no és culpabilitzada, sinó que Chaucer, amb la crua descripció que ens dóna de la nit de noces, ofereix arguments per comprendre el comportament de la noia: ${ }^{4}$

Déu deu saber el que la Maig pensaria quan el va veure assegut amb camisa amb la gorra de nit i el coll tan magre... ${ }^{45}$

A més podem imaginar, encara, que en aquesta història d'un vell luxuriós, però que no pretén fer mal a ningú, Chaucer ha volgut, sempre amb humor i ironia, explorar fins als límits la descripció de la condició de vell que trobem en els tractats clàssics sobre la vellesa, sobretot en el De senectute de Ciceró, que és el que era conegut a l'època. ${ }^{46}$ Cató el Vell, un dels interlocutors del diàleg, diu que ser savi en la vellesa «consisteix en seguir la naturalesa com a guia la més segura i subjectar-se a les seves lleis». ${ }^{47}$ Cató creia que la vellesa és una edat en què els homes han quedat sostrets al jou de les passions, i per tant poden dur una vida moderada, sociable i humana, en definitiva agradable. No obstant, Cató reconeix que el major mèrit de la vellesa és no desitjar la voluptat amb massa afició, perquè no n'està totalment privada, i cita el testimoni d' un ministre del rei Pirros de l'Èpir, Cinees de Tessàlia, que deia «que hi havia un home a Atenes que feia professió de savi; i pretenia que tot quant feim s'ha de dirigir a la voluptat». ${ }^{48}$ És a dir, que per justificar la presència de la voluptat a la vellesa, Cató fa servir l'argumentació d'un epicuri o d'un cirenaic.

Però què passa si a la vellesa la passió no desapareix? Gener, que en altres aspectes és un vell saludable que es pot dir que duu una vida agradable i humana, ha cercat la solució al problema de la voluptat en el matrimoni amb una joveneta. Si ha valgut la pena i si n'ha sortit perjudicat o no, és quelcom que ha de valorar ell sol. Nosaltres, com a lectors, podem dir que Chaucer, fa més de siscents anys, no sabem si amb un coneixement més o menys profund de la filosofia epicúria, va saber resoldre el conflicte amb un humor i una liberalitat que encara avui ens sorprenen i ens diverteixen.

\footnotetext{
${ }^{44}$ Brown (2011: 121-128) comenta que donades les condicions de les dones al s. XIV, és un fet remarcable que Chaucer en les seves narracions els concedeixi importància i poder. A través dels personatges femenins i en el context del matrimoni, vist com un model per a altres cercles socials més amplis, Chaucer explora relacions d'estament, d'identitat i d'autoritat de la seva època.

45 «El conte explicat pel Mercader», vv. 640-642.

${ }^{46}$ En «El conte de Melibeu» hi ha una cita de Cic., CM, VI, 17. Aquest conte està basat en el Liber consolationis et consilii d'Albertà de Brescia (1195-1251), i la cita de Ciceró, igual que moltes altres de la Biblia, deu provenir d'aquest autor. Vegi's Gray (2003).

${ }^{47}$ Cic., CM, II, 5. Trad. de Febrer i Cardona (2002 [1807]).

${ }^{48}$ Cic., CM, XIII, 43. Trad. de Febrer i Cardona (2002 [1807]).
} 


\section{BIBLIOGRAFIA}

ABRAMS, M. H et al. (eds.) (1973³), The Norton Anthology of English Literature, I, New York, Norton Company.

Benson, L. D. (ed.) (19893), The Riverside Chaucer, Oxford, Oxford University Press.

Brown, P. (2011), Geoffrey Chaucer, Oxford, Oxford University Press.

CAIE, G. D. (ed.) (1982), The Merchant's Tale, Beirut, Longman York Press.

CiCERÓ (2002 [1807]), De la Vellesa. De l'amistat, ed. a cura de Paredes, M. i Viana, A., València-Barcelona, Institut Interuniversitari de Filologia Valenciana-Publicacions de l'Abadia de Montserrat. (trad. de Febrer i Cardona, A., El vell Cato o diàlogo sobre la vellesa i Lèlio, o diàlogo sobre l'amistat, Maó, manuscrit de la Biblioteca Victory, 1807).

COOPER, H. (1989), The Canterbury Tales, Oxford, Oxford University Press.

ChAucer, G. (201613), Los cuentos de Canterbury, Madrid, Cátedra. (trad. i notes de Guardia Massó, P.)

EPICUR (2008), Ética, Cànoves i Samalús, Proteus. (trad. i intr. de Jufresa, M.)

FisHer, J. H. (ed.) (1977), The Complete Poetry and Prose of Geoffrey Chaucer, New York, Holt Rinehart and Winston.

Gray, D. (ed.) (2003), The Oxford Companion to Chaucer, Oxford, Oxford University Press. Highet, G. (1986²), La Tradición Clásica, I-II, México, Fondo de Cultura Económica. (trad. s. n., The Classical Tradition, Greek and Roman Influences, Londres, Oxford University Press 1949).

JAUMÀ, J. M. (2018), Chaucer. El conte explicat pel Mercader, trad. inèdita.

JONES, H. (1989), The Epicurean Tradition, London-New York, Routledge.

PANOFSKY, E. (2008), Estudios sobre iconologia, Madrid, Alianza Editorial (trad. de Fernández, B., Studies in iconology, Oxford, Oxford University Press, 1939). 